\title{
PSS AND IPFC POD controllers coordinated tuning by an Adaptive Genetic Algorithm with Hyper-mutation
}

\section{Uso de controladores PSS e IPFC POD para el ajuste mediante un algoritmo genético adaptativo con hipermutación}

\author{
Luis Cordero', Percival Bueno' \\ 'Department of Electrical Engineering, Universidade Estadual Paulista, Ilha Solteira, São Paulo 15385-000,Brasil
}

Recibido (Received): 28/09/2018

Aceptado (Accepted): 15/12/2018

\begin{abstract}
Flexible AC transmission systems (FACTS) are a modern technology to increase controllability in power systems. This work presents an analysis of Interline Power Flow Controller (IPFC) which is a FACTS device. This device control and manage power flow in transmission lines. Supplementary damping controller is installed on IPFC Proportional Integral (PI) control. Power Oscillation Damping (POD) and Power System Stabilizers (PSS) contribute to power system stability. This works represents the electric power system and Interline Power Flow Controller FACTS device by a current sensitivity model (CSM). This work focuses on small-signal stability studies using an Adaptive Genetic Algorithm and Hyper-mutation (AGAH) to design simultaneously controller parameters. Adaptive Genetic Algorithm aims to find optimal controller parameters to enhance greatly stability of the power system. This paper considers two areas 14 bus symmetrical system in order to assess proposed algorithm. Simulations are carried out in MatLab platform in order to compare genetic algorithm with proposed algorithm performance. Results show AGAH outweighed AG by time convergence and accuracy.
\end{abstract}

Keywords: Small-signal Stability, Power System Stabilizers, Interline Power Flow Controller, Power Oscillation Damping, Adaptive Genetic Algorithm, Hyper-mutation.

\section{RESUMEN}

Los sistemas de transmisión de AC flexibles (FACTS) son una tecnología moderna para aumentar la capacidad de control en los sistemas de energía. Este trabajo presenta un análisis de Interline Power Flow Controller (IPFC) que es un dispositivo FACTS. Este dispositivo controla y gestiona el flujo de energía en las líneas de transmisión. El controlador de amortiguación suplementario está instalado en el control integral proporcional (PI) de IPFC. La amortiguación de la oscilación de potencia (POD) y los estabilizadores del sistema de potencia (PSS) contribuyen a la estabilidad del sistema de potencia. Este trabajo representa el sistema de energía eléctrica y el dispositivo Interline Power Flow Controller FACTS mediante un modelo de sensibilidad actual (CSM). Este trabajo se centra en los estudios de estabilidad de pequeña señal que utilizan un algoritmo genético adaptativo y una hipermutación (AGAH) para diseñar parámetros de control simultáneos. El algoritmo genético adaptativo tiene como objetivo encontrar los parámetros óptimos del controlador para mejorar la estabilidad del sistema de energía. Este artículo considera dos áreas 14 de sistemas de bus simétrico para evaluar el algoritmo propuesto. Las simulaciones se llevan a cabo en la plataforma MatLab para comparar el algoritmo genético con el rendimiento del algoritmo propuesto. Los resultados muestran que AGAH superó a AG por la convergencia del tiempo y la precisión.

Palabras Clave: Modelos de Líneas de transmisión, transitorios electromagnéticos, dominio del tiempo, modelo matemático.

\section{INTRODUCTION}

Power System Stability holds great importance when it comes to operation and planning of electric power systems (EPS). Small signal stability studies the electric system performance when it is subjected to small variations [1], [2].

\footnotetext{
* Correspondencia:

E-mail: cordero.lg@gmail.com
}

Therefore, oscillations with low frequencies play an important role.

If these oscillations lack of sufficient damping, it may cause the loss of power system synchronism and with time, it may prevent the connection between neighbouring areas. Electromechanical low frequency oscillation under study are classified as local ( 0.8 to 2.0 $\mathrm{Hz}$ ), inter-area ( 0.2 to $0.8 \mathrm{~Hz}$ ), or intraplant (1.5 to 2.5 $\mathrm{Hz}$ ) [3]. 
These oscillations may compromise EPS lines capacity and system stability. Most electrical power plants have dealt this problem palliative solutions such as PSS installation which inserts additional damping to local mode oscillations.

However, PSS installation does not always offer proper solution to mitigate poor damping oscillation [4].

Studies shows that PSS operates well to damp local mode oscillations but low performance to influence inter-area mode oscillations Thus, control strategies to damp these oscillations are necessary to maintain power system stability. Power System Stabilizer (PSS) and Power Oscillation Damping (POD) provide a supplementary damping to the local mode and interarea oscillation modes, respectively [5].

FACTS stabilizers are usually installed at key points of transmission lines in a power system [6]. IPFC FACTS device is based on voltage source controller (VSC) which mainly compensate and manage power flow (active and reactive) in multiple lines. As a result, voltage profile improves in the surrounding area of FACTS device installation [7].

The supplementary controller of power oscillation damping (POD) is used for IPFC to damp inter-area modes IPFC structure consists of 2 VSC which provide series compensation and a common DC connection that is able to transmit real power to another line. Therefore, this device can supply reactive and real power compensation to alleviate overloaded lines. PSS and IPFC-POD controller design enhance low frequency electromechanical oscillations by proper parameter tuning [8] Recently, Optimization techniques like Bacterial Foraging Optimization Algorithm (BFO), the Particle Swarm Optimization (PSO) [8] and Genetic Algorithm (GA) [9] have been used for the problem of PSS and POD design in a coordinated way. In this paper, an Adaptive Genetic Algorithm [10] with Hypermutation [11] is used for tuning PSS and IPFC-POD controllers in a coordinated way. Coding and simulations are completed in MatLab platform. Results show effectiveness of AGAH compared to GA. This work considers two areas 14 bus symmetrical system [2] and IPFC device which is modelled by a current injection Current.

\section{CURRENT SENTIVITY MODEL}

The CSM is based on Kirchhoff's current law which applies to all dynamic processes in the EPS along anytime. The CSM is a linear analysis tool for EPSs that preserves the external network and there is no need of an infinite bus [8]. What is more, CSM works very well when it comes to adding new equipment such as FACTS devices (IPFC current injection model) to the EPS [12].

\section{INTERLINE POWER FLOW CONTROLLER}

This work considers a IPFC device with two Voltage Source Converter (VSC) technology, which addresses the problem of compensating 2 transmission lines. These VSCs are connected through a common DC link in order to allow active power flow between lines. This capability allows the IPFC to provide both reactive and active power. Therefore, proper adjustment can relieve overloaded lines and thereby optimize the utilization of the overall transmission system [12]. Figure 1 shows three buses $i, j$ and $k$ where IPFC get installed [2]. IPFC structure considers zero net power at the common dc terminals. Therefore, this ideal system losses zero active power [13]. According to active power invariance of IPFC, the equation is as follows (1).

$$
\sum_{n=i, j, k} P_{i n j_{n}}=0
$$

This work considers the VSC as a complex vector which decomposes it into a quadrature component and inphase component by equation (2) [14] where $m=j, k$. By this way, power flow analysis with IPFC-PI control becomes a way easier to solve it out.

$$
\boldsymbol{V}_{p q m}=V_{q m}+j V_{p m}
$$

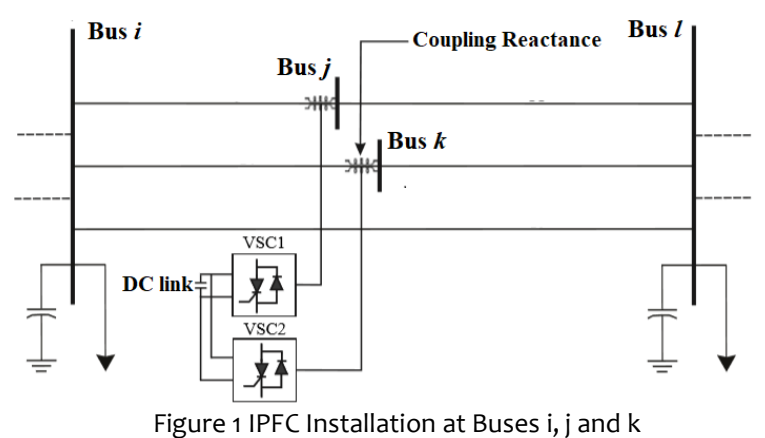

Management power flow strategy used for the IPFC is based on PI controllers. PI controllers are powerful tools for power flow control by boosting voltage levels and small-signal stability [14]. Differential Equations from (3) to (6) represents PI control. PI controllers gains are $K_{1}, K_{2}$ and $K_{3}$ in p.u and PI time constants are $T_{1_{j}}$, $T_{2 j}$ and $T_{3_{j}}$ in seconds..

$$
\begin{gathered}
\dot{V}_{p j}=\frac{K_{1}}{T_{m p}}\left(P_{r e f_{j}}-P_{l_{j}}\right)+\frac{1}{T_{m p}} X_{1}+\frac{1}{T_{m p}} V_{\text {sup }} \\
\quad-\frac{1}{T_{m p}} V_{p j} \\
\dot{X}_{1}=\frac{1}{T_{1 i}}\left(P_{r_{e f}}-P_{l_{j}}\right) \\
\dot{V}_{q j}=\frac{K_{2}}{T_{m p}}\left(Q_{r e f_{j}}-Q_{l_{j}}\right)+\frac{1}{T_{m p}} X_{2}-\frac{1}{T_{m p}} V_{q j} \\
\dot{X}_{2}=\frac{1}{T_{2 i}}\left(Q_{r e f_{j}}-Q_{l_{j}}\right)
\end{gathered}
$$




$$
\begin{aligned}
& \dot{V}_{p k}=\frac{K_{3}}{T_{m p}}\left(P_{r e f_{k}}-P_{l_{k}}\right)+\frac{1}{T_{m p}} X_{3}-\frac{1}{T_{m p}} V_{p k} \\
& \dot{X}_{3}=\frac{1}{T_{3 i}}\left(P_{r e f_{k}}-P_{l_{k}}\right)
\end{aligned}
$$

Equation (3) and (4) relates to active power flow control at bus $j$. Where $V_{\text {sup }}$ is a supplementary signal from the POD controller which modulates the quadrature component $V_{p_{j}}$ of the prime VSC converter in order to provide additional damping to ESP oscillations [8]. Equation (5) and (6) relates to reactive power flow control at bus j. Equation (7) and (8) relates to active power flow control at bus k. $P_{r e f_{l j}}, Q_{r e f_{l j}}$ are the active and reactive power flow control set-points for one transmission line. $P_{r e f_{l k}}$ is the active power flow control set-point for the other line [14]. $T_{m_{p}}$ represents inherent delay of the control device which varies between 1 to $10 \mathrm{~ms}$.

Equations (9)-(11) are the controlled flows at bus $j$ and $k$ $\left(Q_{l j}, P_{l j}\right.$ and $\left.P_{l k}\right)$.

$$
\begin{aligned}
& P_{l j}=-V_{i} V_{j} b_{i j} \sin \theta_{i j}-V_{j} b_{i j}\left(V_{q j} \sin \left(\theta_{i j}\right)\right. \\
& \left.+V_{p j} \cos \left(\theta_{i j}\right)\right) \\
& q_{k j_{k}}=V_{j}^{2} b_{i j}-V_{i} V_{j} b_{i j} \operatorname{coss} \theta_{i j j} \quad \Delta V_{2_{k}} \\
& \Delta P_{k m} \quad-V_{j} b_{i j} A\left(Y_{q j} \cos \left(\theta_{i j} \lambda\right) Y_{2}\right. \\
& \left.-V_{p j} \sin \left(\theta_{i j}\right)\right) \\
& P_{l k}=-V_{i} V_{k} b_{i k} \sin \theta_{i k}-V_{k} b_{i k}\left(V_{q k} \sin \left(\theta_{i k}\right)\right. \\
& \left.+V_{p k} \cos \left(\theta_{i k}\right)\right)
\end{aligned}
$$

\section{A. IPFC Current Injection Model}

IPFC current injection model at buses $i, j$ and $k$ are described by equations (12)-(17). Figure 2 shows current injection at buses $i, j$ and $k$.

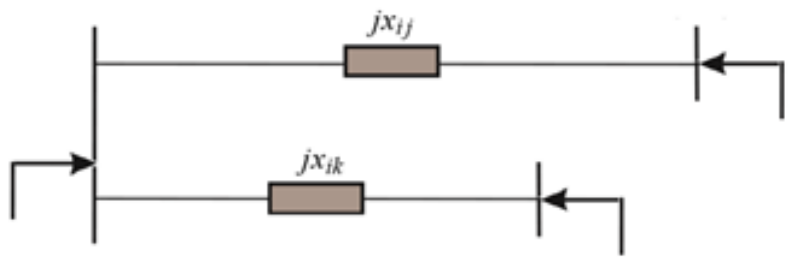

Figure 2 IPFC current injection at buses i, j and $\mathrm{k}$

These equations do not depend on voltage series converter parameters but quadrature and in-phase components of VSC which is a way easier to use them [12].

$$
\begin{aligned}
I_{i n j_{i r}} & =-\sum_{n=j, k} b_{i n}\left(V_{p n} \cos \theta_{i}+V_{q n} \sin \theta_{i}\right) \\
I_{i n j_{i m}} & =\sum_{n=j, k} b_{i n}\left(V_{q n} \cos \theta_{i}-V_{p n} \sin \theta_{i}\right) \\
I_{i n j_{j r}} & =b_{i j}\left(V_{p j} \cos \theta_{i}+V_{q j} \sin \theta_{i}\right) \\
I_{i n j_{j m}} & =b_{i j}\left(V_{p j} \sin \theta_{i}-V_{q j} \cos \theta_{i}\right) \\
I_{i n j_{k r}} & =b_{i k}\left(V_{p k} \cos \theta_{i}+V_{q k} \sin \theta_{i}\right)
\end{aligned}
$$

$$
I_{i n j_{k m}}=b_{i k}\left(-b_{i k} V_{q k} \cos \theta_{i}+V_{p k} \sin \theta_{i}\right)
$$

Where $b_{i k}$ represents $-\frac{1}{x_{i n}}$ and $n=j, k$. Equation (12) and (13) are real and imaginary current injection at bus i. Similarly, equations (14) and (15) works similar to (16) And (17) which are real and imaginary current injection at bus $j$ and $k$, respectively.

\section{PSS AND POD CONTROLLER STRUCTURE}

Figure 3 shows PSS and POD control structures which are quite similar. They differ from each other because input and output signals. PSS input signal comes from generators speed $\left(\Delta \omega_{k}\right)$ and its output signal links to AVR voltage reference. IPFC-POD input signal uses active power flow $\left(\Delta P_{k m}\right)$ which has an impact over inter-are mode and its output signal links IPFC-PI voltage quadrature component [8]. PSS and POD washout time constants are $T_{\omega p s s}$ and $T_{\omega p o d}$ [12]. Phase lead-lag time constants are $T_{1}, T_{2}, T_{3}$ e $T_{4}$. This paper considers $T_{\omega p s s}=T_{\omega p o d}=1 \mathrm{~s}, T_{1}=T_{3}$ and $T_{2}=T_{4}[1]$, [2] and [5]. Stabilizing gains are $K_{\text {pss }}$ and $K_{\text {pod }}$.

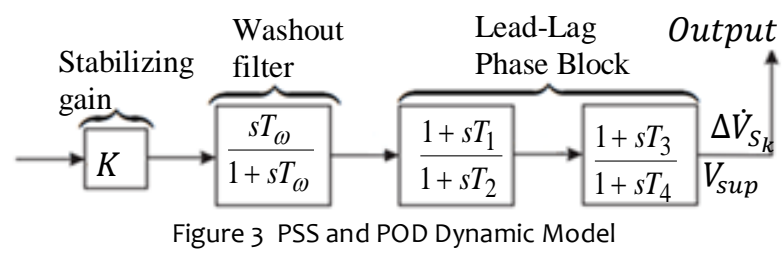

Equations that describe PSS and POD dynamic control upon supplementary damping signals are show in (18) (26).

$\Delta \dot{V}_{1_{k}}=\Delta \dot{\omega}_{k} K_{E S P}-\frac{1}{T_{\omega}} \Delta V_{1_{k}}$

$\Delta \dot{V}_{2_{k}}=\frac{1}{T_{2}} \Delta V_{1_{k}}+\frac{T_{1}}{T_{2}} \Delta V_{1_{k}}-\frac{1}{T_{2}} \Delta V_{2_{k}}$

$\Delta \dot{V}_{S_{k}}=\frac{1}{T_{4}} \Delta V_{2_{k}}+\frac{T_{3}}{T_{4}} \Delta \dot{V}_{2_{k}}-\frac{1}{T_{4}} \Delta V_{S_{k}} \quad I_{\text {inj }_{j r}}+j I_{\text {inj }}(20)$

$\Delta \dot{E}_{f d_{k}}=\frac{K_{r}}{T_{r}} \Delta V_{S_{k}}+\frac{K_{r}}{T_{r}} \Delta V_{r e f_{k}}-\frac{K_{r}}{T_{r}} \Delta V_{k}-\frac{1}{T_{r}} \Delta E_{f d_{k}}$

$\Delta Y_{1}^{\prime}=K_{P O D} \Delta P_{k m}-\Delta Y_{1}$

$\Delta \dot{Y}_{2}=\frac{1}{T_{p 2}}\left[\Delta Y_{1}^{\prime}\left(1-\frac{T_{p 1}}{T_{p 2}}\right)-\Delta Y_{2}\right]$

$I_{i n j_{k r}}+j I_{i n j_{k}(23)}$

$\Delta \dot{Y}_{3}=\frac{1}{T_{p 4}}\left[\left(\Delta Y_{2}+\frac{T_{p 1}}{T_{p 2}}\left(K_{P O D} *\left(\Delta P_{k m}\right)-\Delta Y_{1}\right)\right)(1-\right.$

$\left.\left.\frac{T_{p 3}}{T_{p 4}}\right)-\Delta Y_{2}\right]$

$\dot{V}_{p j}=\frac{K_{1}}{T_{m p}}\left(P_{r e f_{j}}-P_{l_{j}}\right)+\frac{1}{T_{m p}} X_{1}+\frac{1}{T_{m p}} V_{s u p}-\frac{1}{T_{m p}} V_{p j}$

$\Delta P_{k m}=A 1_{k m} \Delta \theta_{k}+A 2_{k m} \Delta \theta_{m}+A 3_{k m} \Delta V_{k}+A 4_{k m} \Delta V_{m}$

$E_{f d k}$ represents field voltage, $\Delta V_{k}$ represents terminal voltage and $\Delta V_{\text {refk }}$ is voltage reference at k-th generator at equation (21). $\Delta P_{k m}$ represents active power variation in a steady state operation.

Revista TECNIA Vol. 28 NN$^{\circ}$ Agosto - Diciembre 2018 


\section{DESIGN OF THE ADAPTIVE ALGORITHM GENETIC WITH HYPERMUTATION FOR TUNING PSS AND POD}

The Adaptive GA operations consist of some key components such as genetic representation, population initialization, fitness function, selection scheme, diversity strategy population, crossover and mutation. Hyper-mutation intervenes selectively speeding up desired fitness at specific generation.

\section{A. Adaptive Genetic Algorithm}

This algorithm has mutation and crossover rates which dynamically calibrates by each generation [10]. Diversity rate are ruled as follows in equation (27).

$\operatorname{Div}_{(q)}=\left(1-\frac{C e q}{n p}\right) * 100$

Where $\operatorname{Div}_{(q)}$ represents Diversity rate, $q$ is current generation and $n p$ is population size. In this paper, $\mathrm{Ceq}$ represents number of prospective individuals in the current population. $\mathrm{Ceq}$ counts those individuals which meet equation (28).

If fitness $(i) \leq \min ($ fitness $)+\frac{D F D}{n p}$

$D F D=\sqrt{\sum_{i=1, n p}(\min (\text { fitness })-\text { fitness }(i))^{2}}$

DFD means Distance Fitness Deviation in equation (28) and (29). Crossover and mutation rate depend on $\operatorname{Div}_{(q)}$. Equation that relate to them are in (30) and (31) where $t r_{(q)}$ and $t m_{(q)}$ are crossover rate and mutation rate, respectively.

$$
\begin{aligned}
& \operatorname{tr}_{(q)}=\left(\frac{D i v_{(q)}}{100}\right) * e^{\left(\frac{D i v_{(q)}}{100}-1\right)} \\
& \operatorname{tm}_{(q)}=\left(1-\frac{D i v_{(q)}}{100}\right) * e^{\left(\frac{D i v_{(q)}}{100}\right)}
\end{aligned}
$$

\section{B. Chromosome Encoding}

PSS1 and PSS2 installation takes places at generator 2 and 3 in the two area symmetrical system [2], [8]. IPFCPOD get installed at bus 7 [12]. Therefore, the chromosome is a vector with size equal to 9. Fig. 4 shows PSS1, PSS2 and POD parameter encoding.

$$
\begin{aligned}
& \begin{array}{|l|l|l|l|l|l|l|l|l|}
\hline T_{1} & T_{2} & K_{P S S} & T_{1} & T_{2} & K_{P S S} & T_{1} & T_{2} & K_{P O D} \\
\hline
\end{array} \\
& \text { PSS1 Parameters PSS2 Parameters POD Parameters } \\
& \text { Figure } 4 \text { Chromosome encoding PSS and POD }
\end{aligned}
$$

POD tuning happen to set first, behavioural population shows that POD tuning is quite decisive to find PSS proper tuning. PSS1 and PSS2 installation takes place in two different areas. IPFC-POD locates strategically at bus 7 which connects a long line transmission that impacts on inter-area oscillations [12].
Fitness function is comprised of the objective function, where $f$ calculates eigenvalues $\left(\lambda_{i}^{\text {calc }}\right.$ ) distance from a desired eigenvalue at specific generation, $x^{g}$ represents best solution at generation $g$. This fitness function considers infeasibility, where $h$ calculates damping $\left(\xi_{i}^{\text {calc }}\right)$ error between the desired value and the current value at generation g. Equation are written in (32) -(34).

$F\left(x^{g}\right)=f\left(x^{g}\right)+\rho h\left(x^{g}\right)$
$f\left(x^{g}\right)=\sum_{i=1}^{n} \mid \lambda_{i}^{\text {calc }}-\lambda_{i}^{\text {des }}$
$h\left(x^{g}\right)=\sum_{i=1}^{n}\left|\xi_{i}^{\text {calc }}-\xi_{i}^{\text {des }}\right|$

One parameter that stands out is $\rho(\rho>>1)$. This work considers $\rho=1000$. By doing so, it places importance over damping values. This fitness function search for the minimum value or in another words, they move closer to the desired damping.

\section{Block Diagram AGA with Hyper-mutation}

Fig. 5a describes coding procedure for the AGAH which solve out the problem in this work. First step generates ten individuals as an initial population in a random way, they go through CSM that considers IPFC-POD and PSS. Second step assesses prospective eigenvalues by the fitness function. Third step begins in 'while loop' condition. Diversity rate starts running and as a consequence crossover and mutation dynamic rates. Hyper-mutation level 1 begins at generation number two in order to boost prospective individuals. An agent searches for desired damping values in the population even though they get spread out in other individuals. This procedure speeds up convergence because it increases the chance an individual mutates with desired damping. Then for the next step the best configurations keep alive for the next generation by means of minimum fitness and it continues until it reaches the stop criterion.

\section{E. Hyper-mutation}

Convergence becomes a big problem for GA due to its constant pace which may lead to long time convergence. On top of that, it substantially depends on initial population. Increasing diversity of prospective individuals speed up convergence. Hyper-mutation enables GA to cope with stagnated fitness. Mutation and Hyper-mutation do not overlap each other. Since mutation help generate new solution [11]. Hypermutation depends on population diversity and it gets activated when $\mathrm{Ceq}$ (maximum number of prospective individuals) keep constant as shown at Fig. 5b. One thing to point out is that the chromosome encoding allows to hyper-mutate PSS genes and POD genes.

\section{Fitness Function}



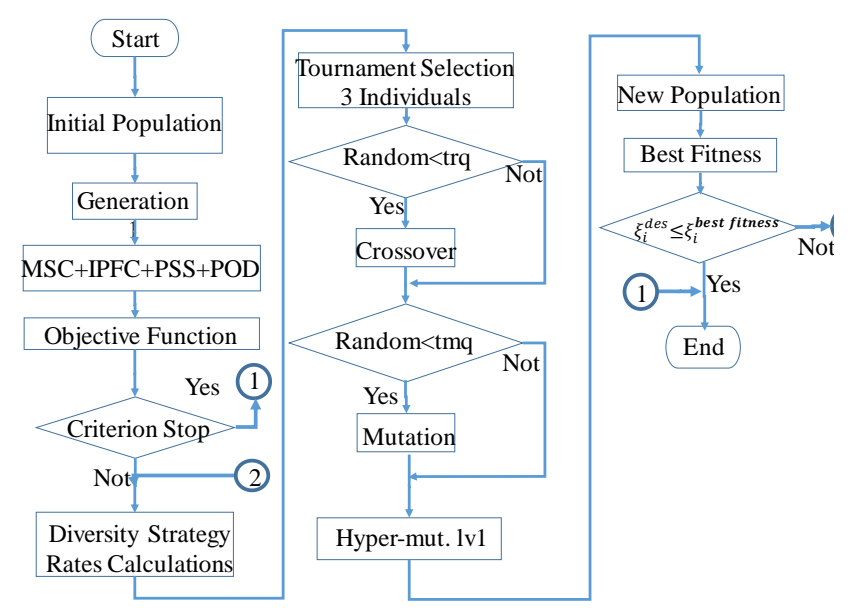

(a)
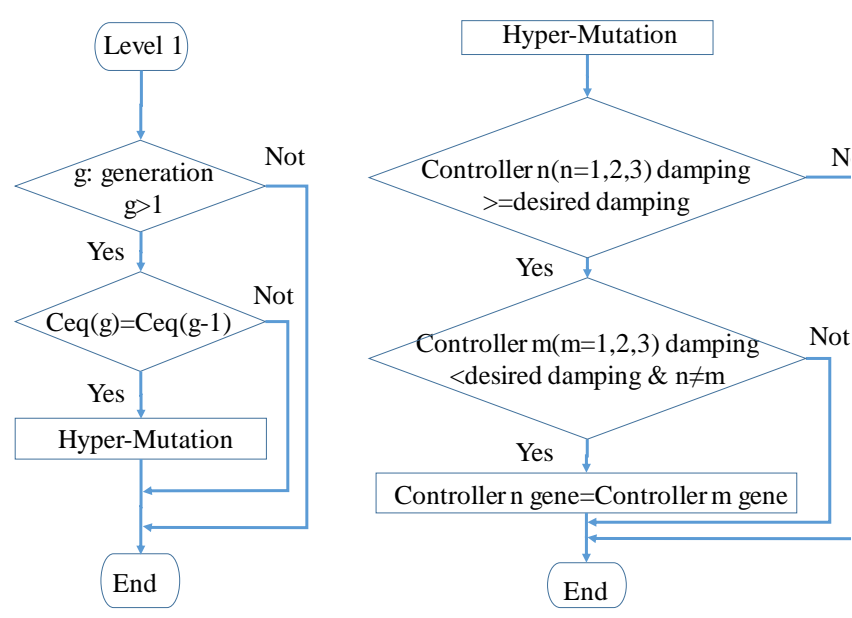

(b)

Figure 5a Block Diagram of AGA with Hyper-mutation and Figure 5 b Hyper-mutation block diagram

\section{VARIABLES CONSTRAINTS}

The AGAH aims to adjust simultaneously the PSS and POD controllers. Lead-lag time constants and stabilizers gains works within a range which is shown in equation (35) and (36).

$0.05 \leq T_{1}$ PSS $\leq 1,0.05 \leq T_{2}$ PSS $\leq 1,1 \leq K_{\text {PSS }} \leq 5$

$0.05 \leq T_{1} P O D \leq 1,0.05 \leq T_{2} P O D \leq 1,0.05 \leq K_{P O D} \leq 5$

IPFC-PI parameters keep fixed [13]: $T_{1 i}=0.0872, T_{2 i}=$ $0.045, T_{3 i}=0.01$ (in seconds), and $K_{1}=3.3492, K_{2}=$ $2.601, K_{3}=1.2761$. These parameters may change and they depend on the system under study.

\section{SIMULATIONS AND RESULTS}

This work uses the two areas 14 bus symmetrical system which has a long line interconnection between bus 7 and 8 . This system has 2 shunt compensation at buses 7 and 8 but it is not enough to enhance voltage drop at bus 7. IPFC-PI installation solved voltage drop out and it also alleviated power flow at buses 7 and 8 . This system has 2 local modes and 1 inter-are mode. PSS1, PPS2 and POD get installed at generator 2 and 3 and at bus 7 , respectively [12].

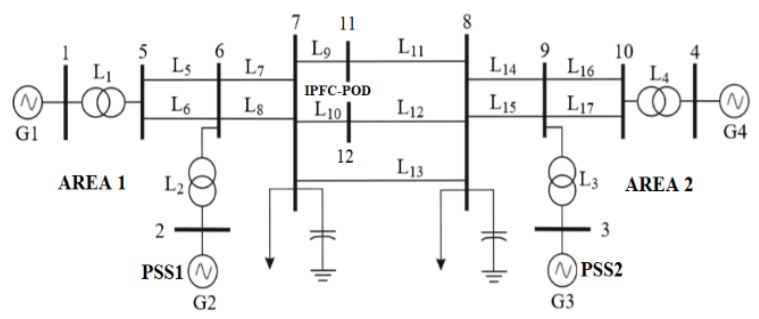

Figure 6 Two areas 14 bus symmetrical system

What is more, table 1 shows that this system has a negative damping value which makes it unstable. Which may undermine system stability if a small power variation or a disturbance takes place at some point in time.

Table 1Benchmark System eigenvalues before and after controller installation

\begin{tabular}{|c|c|c|c|}
\hline Initial & \multicolumn{3}{|c|}{ Eigenvalues without PI, PSS and POD } \\
\hline Mode & $\sigma_{i} \pm j \omega_{i}$ & $\xi_{i}$ & $\omega_{n i}(\mathrm{~Hz})$ \\
\hline$\lambda_{1}$ & $\mathbf{- 0 . 3 6 2} \pm \mathbf{j 6 . 2 9 2}$ & $\mathbf{0 . 0 5 7 5}$ & $\mathbf{1 . 0 0 3}$ \\
& & & \\
\hline$\lambda_{2}$ & $\mathbf{- 0 . 2 6 5} \pm \mathbf{j 5 . 8 8 4}$ & $\mathbf{0 . 0 4 5 0}$ & $\mathbf{0 . 9 3 7}$ \\
\hline$\lambda_{3}$ & $\mathbf{- 0 . 0 6 0} \pm \mathbf{j 4 . 4 5 7}$ & $\mathbf{- 0 . 0 1 3 5}$ & $\mathbf{0 . 7 0 9}$ \\
\hline
\end{tabular}

Table 2 Benchmark System eigenvalues after controllers tuning

\begin{tabular}{|c|c|c|c|}
\hline Final & \multicolumn{3}{|c|}{ Eigenvalues without PI, PSS and POD } \\
\hline Mode & $\sigma_{i} \pm j \omega_{i}$ & $\xi_{i}$ & $\omega_{n i}(\mathrm{~Hz})$ \\
\hline$\lambda_{1}$ & $\mathbf{- 0 . 6 9 2} \pm \mathbf{j 6 . 4 2 6}$ & $\mathbf{0 . 1 0 7 2}$ & $\mathbf{1 . 0 2 8}$ \\
& & & \\
\hline$\lambda_{2}$ & $\mathbf{- 0 . 6 1 3} \pm \mathbf{j 6 . 0 2 4}$ & $\mathbf{0 . 1 0 1 3}$ & $\mathbf{0 . 9 6 3}$ \\
\hline$\lambda_{3}$ & $\mathbf{- 0 . 4 7 8} \pm \mathbf{j 4 . 5 4 4}$ & $\mathbf{0 . 1 0 4 8}$ & $\mathbf{0 . 7 2 7}$ \\
\hline
\end{tabular}

Conventional solutions involve PSS installation but instability menace still remains because poor damping values. IPFC-POD installations comes up as a novel solution to cope with poor inter-area mode oscillations. This section mainly presents simulation results of the AGA with Hyper-mutation which simultaneously tune PPS and POD parameters to achieve desired damping. Table 2 shows eigenvalues after controller coordinated tuning. This paper considers desired damping between 10 and 10.9 percent. It is worth mentioning that computational time becomes rather efficient if desired damping set a range between 10 and 15 or 10 and 30 percent of damping values. The more it reduces damping range, the more time consuming. AGAH and AG perform a hundred tests to assess time convergence, error distance and generation convergence compared to desired damping.

Table 3 shows that AGAH enhances time convergence which is on average 14.66 seconds. On the other hand, GA takes 23.51 seconds on average to converge and generation increases to attain a desired value. 
Moreover, calculated damping are that accurate than AG. Minimum time convergence observed was 6.227 seconds and a maximum 22.9 seconds.

Table 3Time Consuming AGA with Hyper-mutation and AG

Table 3 also shows that AGAH error distance is 0.00720 p.u and it converges at generation 7 on average.

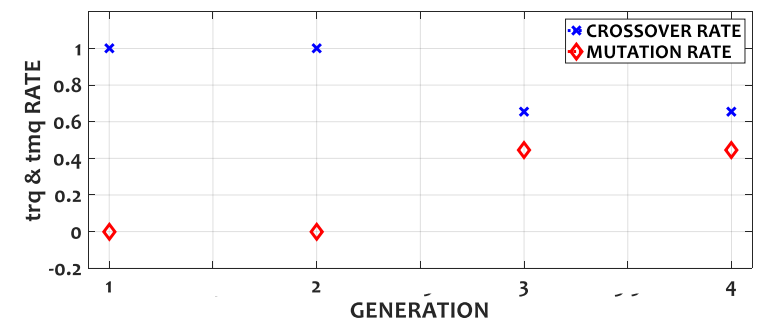

Figure 7 Crossover and Mutation rates by generations

Figure 7 depicts changing rates along generation from 1 to 4. The first two generations work with high crossover rate (cross symbol) and it starts to change dynamically as to adapt by generations. High Mutation rate (diamond symbol) happened at generation 3 and 4 .

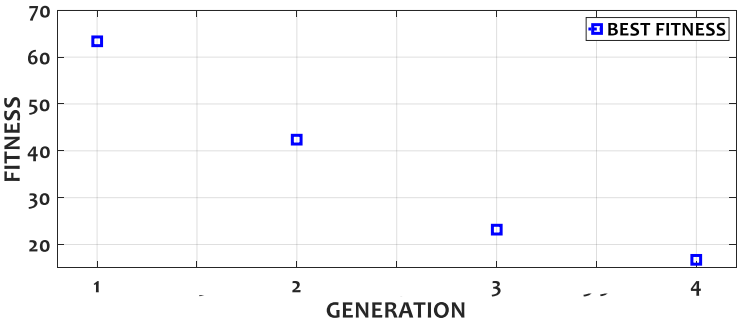

(a)

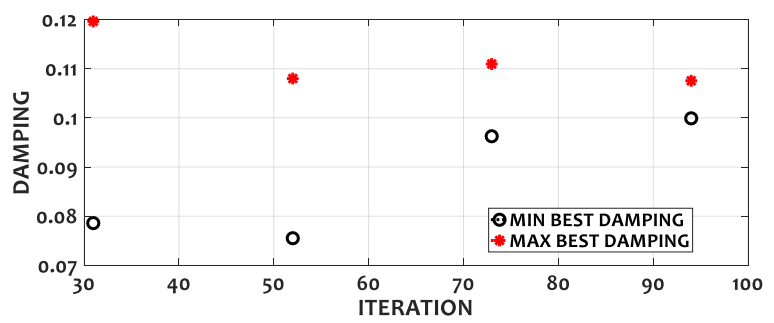

(b)

Figure 8 (a) Best fitness and (b) Damping convergence

Figure 8 (a) depicts how best fitness behaves along four generations until it reaches a desired value. Figure 8 (b) describes best damping at each generation and how it evolves along generations and it seems to become closer around a desired value by each generation. The desired damping is greater than 10 percent but less than 11 percent for local and inter-are modes. $\xi \min \geq 10 \%$

\begin{tabular}{|c|c|c|l|l|l|l|l|}
\hline \multirow{2}{*}{ Algorithm } & \multirow{2}{*}{$\begin{array}{c}\text { Desired } \\
\text { Damping } \\
\text { value }\end{array}$} & \multicolumn{3}{|c|}{ Time (s) } & \multicolumn{3}{c|}{ Error distance } \\
\cline { 3 - 8 } & Avgs & Min & Max & Avgs & Min & Max \\
\hline AGAH & $0.10<\xi \min$ & $\mathbf{1 4 . 6 6}$ & $\mathbf{6 . 2 1}$ & $\mathbf{2 2 . 9 2}$ & $\mathbf{0 . 0 0 7 2 0}$ & $\mathbf{0 . 0 0 1 6 3}$ & $\mathbf{0 . 0 1 3 6 5}$ \\
\hline AG & $0.10<\xi \min$ & $\mathbf{2 3 . 5 0}$ & $\mathbf{6 . 0 3}$ & $\mathbf{3 9 . 5 7}$ & $\mathbf{0 . 0 1 1 1 2}$ & $\mathbf{0 . 0 0 3 0 8}$ & $\mathbf{0 . 0 1 4 5 3}$ \\
\hline
\end{tabular}

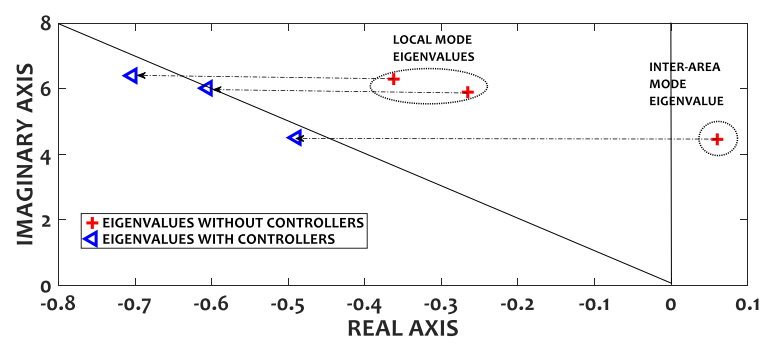

Figure 9 Eigenvalues without and with PSS and POD

Figure 9 describes how initial eigenvalues (asterisk symbol) move toward 10 percent damping region. Final eigenvalues (triangle symbol) get on the desired region with 10 percent of damping as minimum value.

Table 4 PSS1, PSS2 and POD optimal parameters

\begin{tabular}{|l|c|c|c|}
\hline \multirow{2}{*}{$\begin{array}{l}\text { PSS and POD } \\
\text { parameters }\end{array}$} & \multicolumn{3}{|c|}{$10 \% \leq \xi \mathrm{min}$} \\
\cline { 2 - 4 } & PSS G2 & PSS G3 & POD \\
\hline$T_{1}=T_{3}(\mathrm{~s})$ & $\mathbf{0 . 6 5 2}$ & $\mathbf{0 . 7 6 7}$ & $\mathbf{0 . 8 3 2}$ \\
\hline$T_{2}=T_{4}(\mathrm{~s})$ & $\mathbf{0 . 5 2 0}$ & $\mathbf{0 . 6 5 1}$ & $\mathbf{0 . 2 6 4}$ \\
\hline$K$ (p.u) & $\mathbf{2 . 5 1 4}$ & $\mathbf{1 . 9 1 3}$ & $\mathbf{2 . 5 2 5}$ \\
\hline
\end{tabular}

Table 3 shows optimal parameters tuned by AGAH for PSS and POD to damp properly electromechanical oscillation.

\section{CONCLUSION}

In this paper, AGA with Hyper-mutation is used for tuning simultaneously PSS and POD controllers. Significant results obtained from simulations are as follows.

- The solutions achieved for 100 testes of optimizing objective function for PSS and POD parameters show that AGA with Hypermutation yields more accurate damping value than GA.

- $\quad$ AGA with Hyper-mutation time convergence outweighs GA.

- Solutions obtained from AGA with Hypermutation have small standard error deviations.

- AGA with Hyper-mutation tuned successfully PSS and POD which allows to operate with a desired damping value.

- Desired Damping had a narrow range between 10 and 11 percent which may lead 
to long time convergence. However, AGAH successfully performed getting a low time convergence and accurate results.

- $\quad$ AGAH becomes a prominent tool for tuning controller parameters.

\section{ACKNOWLEGMENT}

This study was financed in part by the Coordenação de Aperfeiçoamento de Pessoal de Nível Superior - Brasil (CAPES) - Finance Code 001.

\section{REFERENCES}

[1] P. Anderson and A. A. Fouad, Power system control and stability. New York: Wiley-IEEE Press, 1993.

[2] P. Kundur, Power system stability and control. New York: MacGrawHill, 1994.

[3] P. W. Sauer and M. A. Pai, Power system dynamics and stability. New Jersey: Prentice Hall, 1998.

[4] F. P. De Mello and C. Concordia, "Concepts of synchronous machine stability as affected by excitation control," IEEE Transactions on Power Apparatus and Systems, vol. 88, no. 4, pp. 316-329, 1969.

[5] N. G. Hingorani and L. Gyugyi, Understanding FACTS: concepts and technology of flexible AC transmission system. New York: IEEE, 1999.

[6] L. Gyugyi, K. Sen, and C. D. Schauderr, "The interline power flow controller concept: a new approach to power flow management in transmission systems," IEEE Transactions on Power Delivery, vol. 14, no. 3, pp. 1115-1123, Jul 1999.

[7] D. Valle and P. Araujo, "The influence of GUPFC FACTS device on small signal stability of the electrical power systems," International Journal of Electrical Power \& Energy Systems, vol. 65, pp. 299-306, February 2015.

[8] E. V. Fortes, P. B. Araujo, and L. H. Macedo, "Coordinated tuning of the parameters of $\mathrm{PI}$, PSS and POD controllers using a specialized chubeasley's genetic algorithm," Electric Power Systems Research, 2016, in press.

[9] H. Shayeghi, A. Safari, and H. A. Shayanfar, "PSS and TCSC damping controller coordinated design using PSO in multimachine power system," Energy Conversion and Management, vol. 51, no. 12, pp. 2930 - 2937, 2010.

[10] H. O. Cruz, F. B. Leão, 'Optimal placement fo Fault Indicator using Adaptive Genetic Algorithm', IEEE Power and Energy Society General Meeting, 2017.

[11] H. Cheng, 'Genetic Algorithms with Hyper-mutation for Dynamic Load Balanced Clustering Problem in Mobile Ad Hoc Networks' $8^{\text {th }}$ International Conference on Natural Computation, 2012.

[12] E. V. Fortes, P. B. Araujo, L. H. Macedo, B. R. Gamino, L. B. Martins, 'Analysis of the influence of PSS and IPFC-POD Controllers in Small-Signal Stability Using a Simulated Annealing Algorithm

[13] X.-P. Zhang, "Modelling of the interline power flow controller and the generalised unified power flow controller in newton power flow," IEE Proceedings-Generation, Transmission and Distribution, vol. 150, no. 3, pp. 268-274, May 2003.

[14] J. Zhang, A. Yokoyama, and T. Ide, "Use of IPFC detailed dynamic model for analysis of power flow control and small-signal stability enhancement," IEEJ Transactions on Electrical and Electronic Engineering, vol. 4, no. 5, pp. 654-662, 2009. 